Working Paper 78-2

\title{
UNCERTAIN INFLATION, SYSTEMATIC RISK, AND THE CAPITAL ASSET PRICING MODEL
}

\author{
Thomas A. Lawler
}

\author{
Federal Reserve Bank of Richmond \\ February, 1978
}

The views expressed here are solely those of the author and do not necessarily reflect the views of the Federal Reserve Bank of Richmond. 


\section{Introduction}

The Sharpe-Lintner two-parameter Capital Asset Pricing Model (CAPM) hasbeen the basis for a extraordinary amount of theoretical and empirical work. As originally developed, the CAPM did not explicity account for the effect of uncertain inflation on asset prices. Moreover, almost all major empirical studies of the CAPM have employed nominal rates of return in testing the model. The recent experience of high and variable inflation has led a number of economists to question the validity of a model such as the CAPM which assumes that portfolio decisions are based on nominal instead of real returns. Indeed, Iintner $(1975, \mathrm{p} .11)$ notes that an asset-pricing model which makes this assumption "is misspecified unless the risk premium on all individual stocks is invariant with respect to inflation." Thus any test of the CAPM which utilizes nominal rates of return may be misspecified, and the instability of estimated parameters may be the result of such misspecification.

The purpose of this paper is to examine the effect a change in purchasing power risk may have on an asset's "betá coefficient" (or systematic risk) calculated using nominal rates of return when the response of an asset's nominal rate of return to unexpected price level changes varies across assets. It is shown that this differential response can cause an asset's beta coefficient to be unstable when the degree of inflation uncertainty varies over time. 


\section{The Model}

The following notation is used in deriving the model.

$\widetilde{R}_{i}=$ the nominal return on asset $i$, with mean $E\left(\widetilde{R}_{i}\right)$ and variance $\sigma^{2}\left(\widetilde{R}_{i}\right)$

$\widetilde{R}_{\mathrm{m}}=$ the nominal return on the market portfolio, with mean $\mathrm{E}\left(\widetilde{\mathrm{R}}_{\mathrm{m}}\right)$ and variance $\sigma^{2}\left(\tilde{R}_{m}\right)$.

$\tilde{\pi}=$ the rate of inflation, with mean $E(\tilde{\pi})$ and variance $\sigma^{2}(\tilde{\pi})$.

$R_{f}=$ the riskless nominal interest rate.

Cov = covariance.

Tildes $(\sim)$ denote random variables.

In the traditional CAPM, which ignores purchasing power risk, the equilibrium relationship between the expected nominal return on any asset $i$ and the expected nominal return on the market portfolio is given by

(1) $E\left(\tilde{R}_{j}\right)=R_{f}\left(1-\beta_{i}\right)+\beta_{i} E\left(\tilde{R}_{m}\right)$,

where $\beta_{i}=\operatorname{Cov}\left(\tilde{R}_{i}, \tilde{R}_{m}\right) / \sigma^{2}\left(\tilde{R}_{m}\right)$. Purchasing power risk is introduced here by assuming that the relationship between unexpected changes in the inflation rate and unexpected changes in an asset's nominal return is given

(2) $\quad \tilde{R}_{i}-E\left(\tilde{R}_{i}\right)=b_{i}[\tilde{\pi}-E(\tilde{\pi})]+\tilde{\varepsilon}_{i}$

where $b_{i}=\operatorname{Cov}\left(\tilde{R}_{i}, \tilde{\pi}\right) / \sigma^{2}(\tilde{\pi}), E\left(\tilde{\varepsilon}_{i}\right)=0$, and $\operatorname{Cov}\left(\tilde{\pi}, \tilde{\varepsilon}_{i}\right)=0$.

It is obvious that the various $b_{i}$ 's will vary across assets. For example, an asset yielding a constant nominal rate of return will have a $b_{i}=0$, while an asset yielding a constant real rate of return will have $a b_{i}=1$. The following relationships can be derived from (2) (realizing that (2) also applies to the market portfolio): 
(3a) $\operatorname{Cov}\left(\tilde{R}_{i}, \tilde{R}_{m}\right)=b_{i} b_{m} \sigma^{2}(\tilde{\pi})+\operatorname{Cov}\left(\tilde{\varepsilon}_{i} \tilde{\varepsilon}_{m}\right) ;$

and

(3b) $\sigma^{2}\left(\tilde{R}_{m}\right)=b_{m}{ }^{2} \sigma^{2}(\tilde{\pi})+\sigma^{2}\left(\tilde{\varepsilon}_{m}\right)$.

Assuming that the variance of the inflation rate $\sigma^{2}(\tilde{\pi})$ is a valid measure of purchasing power risk, one can evaluate the effect of a change in purchasing power risk on the slope coefficient of the traditional CAPM equation by calculating $\partial \beta / \partial \sigma^{2}(\tilde{\pi})$. Using ( $3 a$ ) and (3b), one finds that

(5) $\partial \beta_{i} / \partial \sigma^{2}(\tilde{\pi})=\frac{\sigma^{2}\left(\tilde{R}_{m}\right) b_{i} b_{m}-\operatorname{Cov}\left(\tilde{R}_{i}, \tilde{R}_{m}\right) b_{m}{ }^{2}}{\left[\sigma^{2}\left(\tilde{R}_{m}\right)\right]^{2}}$

Equation (5) can be rewritten to obtain

(6) $\partial \beta_{i} / \partial \sigma^{2}(\tilde{\pi})=\frac{b_{m}\left(b_{i}-\beta_{i} b_{m}\right)}{\sigma^{2}\left(\tilde{R}_{m}\right)}$

Obviously, from (6) $\beta_{i}$ will not change if $b_{m}=0--i . e$. , if the nominal return on the market portfolio is invariant with respect to inflation. If $b_{m} \neq 0$, then (6) can be rewritten

(7) $\partial \beta_{i} / \partial \sigma^{2}(\tilde{\pi})=\frac{b_{m}^{2}\left[\begin{array}{l}b_{i} \\ b_{m}\end{array}-\beta_{i}\right]}{\sigma^{2}\left(\tilde{R}_{m}\right)}$,

which implies that
(8a) $\partial \beta_{i} / \partial \sigma^{2}(\pi)>0$ if $\frac{b_{i}}{b_{m}}>\beta_{i}$;
(8b) $\partial \beta_{i} / \partial \sigma^{2}(\pi)<0$ if $\frac{b_{i}}{b_{m}}<\beta_{i}$;

and

(8c) $\partial \beta_{i} / \partial \sigma^{2}(\pi)=0$ if $\frac{b_{i}}{b_{m}}=\beta_{i}$. 
Thus $\beta_{i}$ will only be stable during periods of changing purchasing power risk if a) $b_{m}=0$; or b) $\beta_{i}=b_{i} / b_{m}$. In the case where $b_{m} \neq 0$, this means that $\beta_{i}$ will only be stable if the change in $R_{i}$ relative to $R_{m}$ in response to an unanticipated change in inflation is equal to the change in $R_{i}$ relative to $R_{m}$ when no purchasing power risk exists. This condition will not in general hold for all assets. Thus if $b_{m} \neq 0$ and $\sigma^{2}(\tilde{\pi})$ is not constant over time, then in general $\beta_{i}$ will not be stable over time.

Recent evidence suggests that $b_{m}<0$ for a number of widely used proxies for the market portfolio (Nelson (1976), Bodie (1976)). Moreover, it is apparent that $\sigma^{2}(\tilde{\pi})$ has not been stable in recent years. This implies that the traditional CAPM equation is misspecified, and that any instability found in estimates of the CAPM parameters over time may be the result of changing purchasing power risk. 
Bodie, zvi. "Common stocks as a Hedge against Inflation," Journal of Finance, 31 (May 1976), 459-470.

Chen, A.H. and Boness, A.J. "Effects of Uncertain Inflation on the Investment and Financing Decisions of the Firm," Journal of Finance, 30 (May 1975), 469-483.

Friend, I., Landskroner, Y., and Losq, E. "The Demand for Risky Assets under Uncertain Inflation," Journal of Finance, 31 (December, 1976), 1287-1297.

Lintner, John. "The Valuation of Risk Assets and the Selection of Risky Investments in Stock Portfolios and Capital Budgets," The Review of Economics and Statistics, 47 (February 1965), 13-37.

, "Inflation and Security Returns," Journal of Finance 30(May 1975), 259-280.

Nelson, Charles. "Inflation and Rates of Return on Common Stocks," Journal of Finance, 31 (May 1976), 471-483.

Sharpe, William F. "Capital Asset Prices: A Theory of Market Equilibrium under Conditions of Risk," Journal of Finance, 19 (September 1964), 425-442.

Siegel, J. and Warner, J. "Indexation, the Risk-Free Asset, and Capital Market Equilibrium," Journal of Finance,

32 (September 1977), 1101-1107. 